\title{
Unusual Discovery of an Foreign Body in an Unusual Part of the Aerodigestive Ways
}

\author{
Cristina Otilia Laza* and Dan Mihail \\ ENT /OMF Clinic SCJU SF Apostol Andrei, Constanta, Romania
}

Submission: August 29, 2017; Published: September 07, 2017

*Corresponding author: Cristina Otilia Laza-ENT Senior head and ne ck surgeon ,ENT/OMF Clinic SCJU SF Apostol Andrei Constanta, b-dul Tomis 145, Constanta 900591, Romania, Tel: 40722840980, Email: cristinaotilia@gmail.com

\begin{abstract}
Foreign bodies are an important chapter in ENT practice, every site having his specificity-types of foreign bodies, methods of examination and extractions, complications and problems Beside usual foreign bodies like beans, balls, marbels, magnets, coins, button batery from time to time un unusual foreign body is discovered and every ENT doctor-has his files. The otolaryngologic literature is abundant with case reports of unusual foreign bodies but nasopharyngeal location is rare. Inert foreign can remain in the nasopharynx for prolonged periods of time. Being a blind area, difficult to examine, in the nasopharynx foreign bodies in the nasopharynx are likely to be missed. Endoscopy has revolutionized the otolaryngologist's ability to visualize not only the nasal, sinusal structures but also the nasopharynx, and to localize and remove foreign bodies not visible on anterior rhinoscopy. We present an exceptional case of an foreign body blocked in the nasopharynx almost one year, discovered and removed in course of the adenoidectomy.
\end{abstract}

Keywords: Foreign body aspirated, Nasopharynx, Adenoids, Adenoidectomy

\section{Case Presentation}

We present the case of a small male patient of 5 years old, who was sent to the clinic for chronic bilateral nasal obstruction and cronic rhinorrhea, especially posterior, morning cough, nocturnal sniffing with short breathing episodes, bilateral hearing loss. Also his mother describe lack of appetite, inattention, lack of concentration, repeated rhinitis, tonsillitis, otitis. History of atopy-alergical rhinitis, adenoids in the familyhis father, repeated episodes of respiratory infections [1-3].

\section{ENT Clinical Exam}

Child with mildly retarded mood, hade staturoponderal hypotrophy, -pectus carinatus escavatus adenoidian facies ,with mouth opened, lack of development of the maxilla with retracted superior lip, rinolalie closed.halitosis, ogival palatine volt, oropharyngeal istmus completly blocked by enlargement of the palatine tonsils ,on the posterior wall of the oropharynx descend the inferior pole of the pharyngeal tonsil -adenoids .Nasal cavities were narrowed by the hypertrofied mucosa at the level of the turbinates with a pale ,purple colour like in alergy Micropoliadenopathy cervical on jugulo-carotid chains is a result of repetead respiratory infections .

a) The general pediatric assessment has established: staturo-ponderal hypotrophy, pectus escavatus, nocturnal enuresis, lack of concentration and attention, snoring with sleep apnea syndrome.

b) The laboratory usual tests, X-ray lung were normal,immitance audiometry-aspect type B-serous otitis Chronic adenoiditis, hypertrophic tonsilitis, Sleep apneea sdr ,Chronic serous otitis were diagnosed and this surgical case was treated by adenoidectomy, under general anesthesia of IOT [4-6].

After induction of general anestesia we remove a very large mass of adenoids and we feel something bony in contact with the instruments, thinking of a posible longer pharyngeal spine. so we prefere a, direct visual inspection of the cavum with an elevator for oft palate than with an endoscope. It was a good idea because we discover a foreign body-a vertebra from a chicken throat crowned under Skull base, necrotic / osteotic green and fetide, surouded by adenoid tissue. The shock was when after the extraction of the foreign body,my team freeze for a minute when they saw a vertebra in my adenotom, than after the complete silence a voice-one of my residents desperate almost crying was heard -,,'doctor you remove the vertebra of the child ",-I look around me-everyone was disturbed, I remember the face of the anestesiologist in his first day on ENT , and I understand that I 
have to explaine that it was a foreign body and it is a vertebra from a chicken neck, with infection, osteitic-so old hidden in the mass of adenoids.Till the return of the whole team from the surprise, I inspect the foreign body, and I remember to my resident anatomy of the cervical spine and size in children. Than the cavity was examined directly for any signs of osteitis of the cavity walls, washed with hydrogen peroxide and irrigated with antibiotic solutions. The child followed a week of IV antibiotic treatment and local nasal anti-inflammatory and decongestants / antiseptics.

After the surgery I discuss with the mother of the child and she remember that one year ago the child suffered a severe dyspnea with syncope (penetration syndrome) at dinner -he chocked eating chicken soup, Mother forced the child to vomite by inserting her finger in the neck which led to the normalization of his condition. Later she call the ambulance and was transported in emergency, where the child was examined by a qualified practitioner who examine child, asked for simple cervical, thoracic and abdominal radiographs without finding the foreign body. The ENT physician's examination of the oral cavity, pharynx, cervical examination did not provide significant clinical data, which led to the conclusion that it had descended into inferior digestive tract due to the good condition of the child, lack of swallowing or breathing disorders. The child was discharged with a diagnosis of digital postraumatic pharyngitis, and his mother was instructed about the diet and the complications that may occur and how to follow the foreign body in child stool. After the initial event, the child began to develop bilateral nasal obstruction and anterior and posterior purulent rhinorrhea with nocturnal and morning productive cough and repeated episodes of respiratory infections. The mother was sporadic to her general physician the following year for more and more nasal obstruction and episodes of purulent rhinorrhoea, the child being treated with numerous nasal antibiotics and disinfectants, eventually diagnosed with adenoiditis, which caused her mother to ask opinion of different ENT doctor and finally she accept the surgery[6-8].

After our discution, I was forced to explain her the risk and complications possible and she understand why is important to remaine longer in the hospital for imagistic studies and treatment. At regular controls, the child presented with good general condition, normal breathing, without rhinorrhea or cough, and the serous otitis was resolved by returning the impedance to the A type and returning the appearance and mobility of the eardrum to normal. The child was than treated with multivitamines and general vaccines to increase immunity which resulted in cessation of recurrent infections, gained weight by returning appetite, and growth returned to normal.

\section{Positive Diagnosis}

a) A simple lateral X-ray of the nasopharynx confirms the diagnosis of a radio-opac foreign body. b) Palpation of the cavum is a possibility.

c) With anterior rhinoscopy is not always possible to see the nasopharynx.

d) But is possible with the posterior rhinoscopy or with a soft palate elevator, direct emdoscopy of the rhinopharynx.

e) The basic test for foreign body diagnosis in nasopharynx is nasal endoscopy. CT and MRI may be more accurate, but with high costs, irradiation, plus MRI contraindications, it is recommended to perform them only in complications: meningitis, orbital cellulitis, cavernous sinus thrombophlebitis, retropharyngeal abscess $[9,10]$.

\section{Ways of Incorporation in the Cavum}
a) A foreign body originally nasal pushed.
b) Blow-nose-blowing effort on the nose, by defeating the Velopalatine isthmus.
c) Iatrogen-a broken cavity instrument, a postoperator forgotten gauze / or pack, the oliva of a probe on the nose.

\section{Complications}

A potentially fatal complication is sudden air obstruction by falling into the lower respiratory tract to extraction attempts, or blowing the nose vigorously or in sleep.

I. Superinfections with suppurative rhinosinusitis, maxilo-etmoidal usual, halitosis, cacosmia.

II. Repeated episodes of epistaxis.

III. Skull base osteitis, vertebral osteitis.

IV. Meningitis.

V. Cavernous sinus thrombophlebitis.

VI. Retrofaringian abscess.

\section{Treatment}

a) Extraction under general anesthesia with intubation to secure the airway.

b) transoral, transnasal, rarely transpalatal or external paralateronasal or like in «midfacial degloving» in very large complicated foreign bodies.

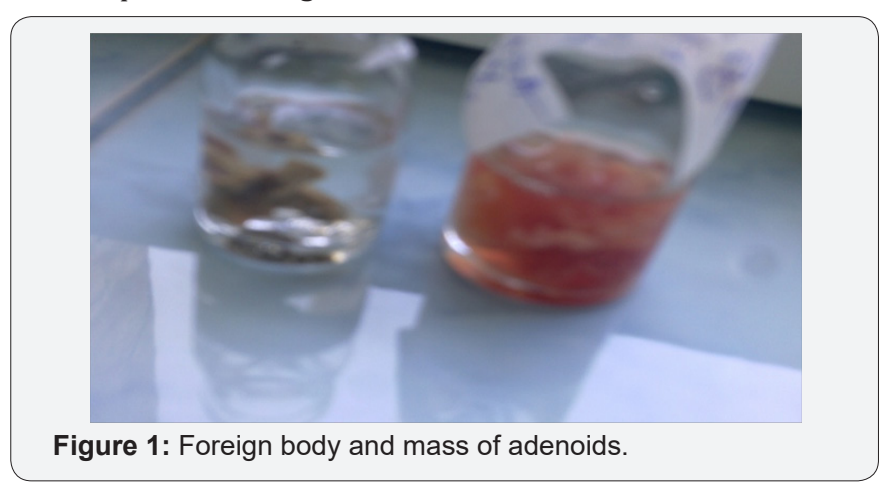




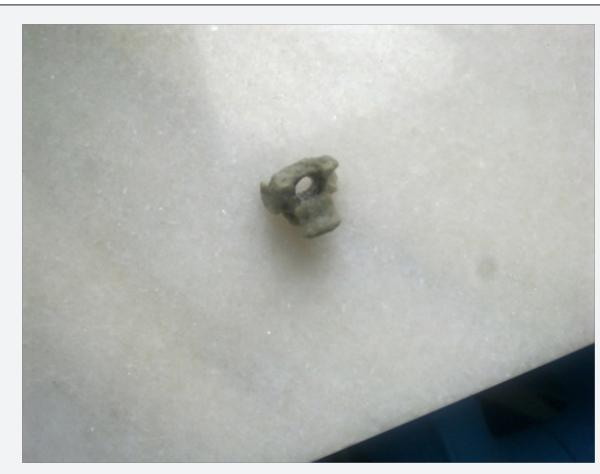

Figure 2: Foreign body-chicken neck vertebra.

At repeted follow up the evolution of the child was normal good with good general status, good, normal breathing ,no rinoreea ,no deafness-immitance audiometry return to type A normal, normal aspect of the eardrum. The child was than sustained with vitamins and general polivaccine, so the recurrent infections stoped he gain in weight and heights (Figures 1 \& 2).

\section{Discussion}

Foreign bodies can reach the nasopharynx either through the nose or through the oropharynx and rarely a penetrating foreign body may lodge in the nasopharynx. Foreign bodies introduced into the nose are a common occurrence in children who out of curiosity or boredom want to explore the body orifices and thus any object small enough to enter the anterior nares has been removed from the nasal cavity. In adults, nasal foreign bodies are seen usually in mentally deranged individuals or may reach accidentally. Foreign bodies in the nose typically lodge near the floor of the nose below the inferior turbinate though these can be seen in any part of the nasal cavity. Attempts at removal of such foreign bodies by the patients themselves or those around can push them back into the pharynx and occasionally these may get lodged in the nasopharynx. Most of the foreign bodies entering the oral cavity pass into the esophagus and some are inhaled into the trachea. It is unusual for a foreign body taken orally to enter in the nasopharynx for various resones

a) Attempts at digital removal,

b) Regurgitation due to vomiting or coughing.

c) Or if the foreign body is put into the mouth in lying down position with the neck extended.

d) Large size of the foreign body has been cited as another factor.

Adults may localize the foreign body in the nasopharynx but children may not be able to do the same. Posterior rhinoscopy where is possible can be helpful for diagnosis

a) X-rays of the neck, chest and abdomen in children presenting with foreign body ingestion.

b) X-ray lateral view of the rhinopharynx if the foreign body cannot be found in the aerodigestive tract. c) Digital examination of the nasopharynx in the absence of nasal endoscope, detect the presence of a foreign body in the nasopharynx, must be avoided in case of sharp foreign body.

d) Endoscopic examination under general anesthesia or local anaesthesia in co-operative children. Is the best method to diagnose nasopharyngeal foreign bodies?

e) Direct exposure of the nasopharynx by retraction of the soft palate with catheters could be helpful in large sized blunt foreign bodies [11].

\section{Treatment}

i. Instrumental removal, of foreign bodies.

ii. Positive pressure technique.

iii. Use of Foley's catheter or Fogarty balloon and even cyanoacrylate glue.

iv. Magnets.

v. Nasal endoscopy is the only method of proper visualization but for extraction of the foreign bodies especially sharp whose retrieval can cause damage to the surrounding tissues.

vi. Perforation of the pharyngeal wall is a real threat and retropharyngeal abscess formation has been reported.

\section{Conclusion}

a) Nasopharynx can be the site for lodgement for foreign body ingestion even is a very rare location.

b) If a radio-opac foreign boy is not visible on X-rays of the neck, chest and abdomen, lateral view of the nasopharynx should be included in the films.

c) In case of non radio-opaque foreign bodies, digital palpation of the nasopharynx is useful but should be avoided in case of sharp foreign bodies.

d) Nasopharyngoscopy is extremely useful for diagnosis and removal of foreign bodies from the nasopharynx.

e) A foreign body in this position is extremely rare.

f) In our patient the hypertrophy of the lymphoid tissue trapped the bone and prevents complications.

g) Finally nasopharynx is an unusual place for a foreign body [12].

\section{References}

1. WA Webb, L Mc Daniel, L Jone (1984) Foreign bodies of the upper gastrointestinal tract: Current management. South Med J 77(9): 1083-1086.

2. JK Hamilton, DE Potter, Philadelphia (1993) Gastrointestinal foreign bodies. In: Gastrointestinal disease: Pathophysiology, Diagnosis and Management, In Sleisenger MH, Fordtran JS, WB Saunders (eds): 286292. 
3. GJ Herrantz, VJ Martinez, SA Garcia (1991) Esophageal foreign bodies in adults. Otolaryngol Head Neck Surg 105: 649-654.

4. Vele DD, Dubey SP (1997) An unusual foreign body: a whole fish in the throat. Auris Nasus Larynx 24(2): 207-209.

5. Deidiker R (2002) Return of the killer fish: accidental choking death on a bluegill (Lepomis macrochirus) American Journal of Forensic Medicine and Pathol 23(2): 197-198.

6. Kalan, M Tariq (2000) Foreign bodies in the nasal cavities: a comprehensive review of the aetiology, diagn. pointers, and therapeutic measures. Postgrad Med J 76: 484-487.

7. MM Sangeeta, RS Greval, D Singh (1999) Paediatric nasopharyngeal foreign bodies. Indian J Otolaryngol Head Neck Surg 51(1): 80-82.
8. PK Majumdar, AK Sinha, PB Mookherje, SN Ganguly (1999) An unusual foreign body (10 N.P. Coin) in nasopharynx. Indian J Otolaryngol Head Neck Surg 52(1): 93.

9. SC Sharma, S Bano (1992) An unusual foreign body in nasopharynx. Indian J Otolaryngol Head Neck Surg 1: 42-43.

10. JH Faraj (1993) Upper airway obstruction by ascaris worm. Can J Anesth 40(5): 471-482.

11. B Singh, EL Gady Har, M Kantu (1997) Complications associated with 327 foreign bodies of the pharynx, larynx and esophagus. Ann Otol Rhinol Laryngol 106(4): 301-304.

12. FO gut, M Bereketoglu, C Bilgeric, S Totan (2000) Metal ring that had been lodged in a child's nasopharynx for 4 years. Ear Nose Throat J 80(8): 235-236.

\section{Your next submission with Juniper Publishers will reach you the below assets}

- Quality Editorial service

- Swift Peer Review

- Reprints availability

- E-prints Service

- Manuscript Podcast for convenient understanding

- Global attainment for your research

- Manuscript accessibility in different formats

( Pdf, E-pub, Full Text, Audio)

- Unceasing customer service

Track the below URL for one-step submission https://juniperpublishers.com/online-submission.php 